\title{
Budgetary allocation and organizational characteristics of higher education institutions: a review of existing studies and a framework for future research
}

\author{
Benedetto Lepori · John Usher • Martina Montauti
}

Published online: 18 October 2012

(C) Springer Science+Business Media Dordrecht 2012

\begin{abstract}
Budgeting - i.e. the decision on the level of expenditures and on the repartition of resources among organizational subunits - can be conceived as a critical organizational process, which is closely related to key choices concerning strategic priorities and to resources acquisition strategies. Overall, it is increasingly being recognized as one of the central places where steering and governance take place, and where higher education institutions are supposed to take initiative. Accordingly, this paper pursues two aims: first, it provides a review of existing studies about budgeting in higher education, according to the literature on changes in its organizational characteristics, and with a focus on approaches from Organizational Theory and Sociology. Second, it identifies some future directions of research, thus easing the integration of these two bodies of literature. This integration may help in providing researchers with a deeper understanding of the current functioning of budgeting processes, their variations across higher education institutions and countries, as well as their implications for organizational behavior.
\end{abstract}

Keywords Budgeting · Higher education institutions · Universities · Change

\section{Introduction}

It is impossible to overestimate the importance of budgeting in public and private organizations, as well as in public administration (Wildavsky 2002). Critically, budgeting provides for the repartition of resources to organisational subunits thus impacting on their activities and creating incentives for actors' behaviour (Gautier and Wauthy 2007). At the level of the whole organization, budgeting can be recognized as a central element in the organizational control systems that keep a balance between revenues and expenditures,

B. Lepori $(\bowtie) \cdot$ M. Montauti

Centre for Organisational Research, Faculty of Economics, University of Lugano, Lugano, Switzerland e-mail: blepori@usi.ch

J. Usher

Policy and Strategy, Faculty of Management, University of Lethbridge, Lethbridge, AB, Canada

e-mail: john.usher@uleth.ca 
manage the resources interface with the environment, and reduce uncertainty (Pfeffer and Salancik 1974). Budgeting is also connected to strategic decision-making since implementation of strategies is likely to require also reallocation of financial means (Jarzabkowski 2002). Budgeting is also a central variable in the consideration of internal power balance. Endowment of resources flowing from budgetary outcomes can be seen as a signal of power with broad impacts on internal power balances, while reciprocally, departmental power can itself be used to acquire resources (Salancik and Pfeffer 1974). Finally, the process of budgeting is a cultural and symbolic act, which displays and enacts organizational goals and norms through selective allocation of resources (Lascoumes and Le Gales 2007). Budgeting is thus not only an instrument to legitimize organizations with respect to important institutional players in their environments, but also to maintain organizational identity and to promote collective action.

With respect to higher education institutions (hereafter HEIs), existing studies concerning budgeting mostly analyse one or a few individual institutions, and focus on single issues, like the role of power (Pfeffer and Moore 1980) or the impact of national funding systems on budgeting (Jongbloed 2007). These works are related to different traditionsEconomics, Organizational Studies, Accounting, Higher Education Studies—and thus it is difficult to get an overview that might highlight similarities and differences among them.

This paper is based on on-going work in the EUROHESC project about the transformation of universities in Europe (TRUE). Its aim is first to review existing studies of higher education budgeting - with a focus on approaches from organizational theory and sociology - in light of the literature on changes in the organizational characteristics of HEIs. The second aim of this paper is to identify some future directions of research, which would facilitate the integration of these two bodies of literature. It is hoped that such an integration will provide researchers with a deeper understanding of the current functioning of HEI budgeting processes, their variations across HEI and countries and their implications for organizational behavior overall.

We realize this program as follows. In Sect. 2 of the paper, we provide a descriptive analysis of budgeting processes, highlighting their connections with other organizational characteristics of HEIs and introducing some basic dimensions for comparative analysis. In Sect. 3, we review existing studies of HEIs' budgeting processes organized according to their underlying theoretical conceptions of organizations and actors' behavior. In the two following sections, we highlight two directions of research, focusing on the relationship between organizational restructuring of HEIs and budgeting (Sect. 4), as well as on organizational responses to changes in national funding systems (Sect. 5). We conclude the paper with some broad remarks on the significance of the study of budgeting for higher education studies overall.

\section{Budgeting in higher education institutions: a general description}

In its simplest way, budgeting can be defined as an organizational process through which centrally available financial resources are divided among organizational subunits and type of expenditures (Jongbloed and van der Knoop 1999). In almost all cases, its outcome will be a formal document specifying the level of resources allocated for a given period of time-in most cases the following year. Budgeting has thus to be carefully distinguished from accounting, where expenditures incurred in a given period of time are reported.

In most countries, HEI funding is composed by two main approaches (Lepori et al. 2007; Jongbloed 2008). In the first, resources are attributed to the HEI as a whole and then 
distributed internally to subunits (core budget). In the second, resources are earmarked to specific activities and subunits (third-party funding). The former is mostly composed of the basic operational grant from the State, supplemented in most cases by undergraduate fees, donations and other general revenues. Third-party funding is generally composed of public research grants, private contract funds, postgraduate fees and other earmarked revenues.

As typically defined, budgeting at the HEI level concerns only the core budget, while third-party funds - even if included in institutional accounts - are under the responsibility of subunits. However, since many activities are funded through both sources, there are interdependencies between the two streams of resources. For example, some research grants might accrue overheads directly to an HEI to cover the general costs of conducting research on university premises. Conversely, many HEI have developed policies where the provision of core funding is partially related to the acquisition of third-party funds. Policies concerning the management of third-party funds, as well as the share of the two streams of resources, might thus have a strong impact on institutional budgeting, an issue which has been hardly addressed in past studies.

Given its centrality in organizational life, an analysis of budgeting can take different perspectives. In the following, we present four perspectives which emphasize: (1) the material side-budgeting as a tool to distribute scarce resources, (2) the relationship of budgeting to organizational actors and their interests, (3) the procedural, rule-based dimension and, (4) the relationships of budgeting with broader cultural dimensions and social norms.

Budgeting as part of the resources flow

In its material dimension, budgeting is a part of the economic cycle wherein the HEI acquires resources from different sources and divides them among organizational subunits-faculties, departments, research centers, services-in order to realize activities which potentially lead to the acquisition of further resources. This direct connection with the material environment is a distinctive characteristic of budgeting, which differentiates it from other organizational processes such as strategizing. However this connection also raises issues of rivalry among institutional subunits vying for scarce resources and of the optimal allocation of resources in order to achieve organizational goals (Massy 1996b).

This perspective also highlights the close relationship between resource acquisition and the structure of the resource environment, as two central functions of budgeting are to keep a balance between revenues and expenditures. Thus, budgeting has a dual function; as an instrument to internally allocate resources, but also as a tool to acquire resources by making different types of claims on the State (Covaleski and Dirsmith 1988).

Accordingly, a central factor to be taken into account in the analysis of HEI budgeting and its variations is the structure of the resource space and, especially, of variations in public higher education funding. One approach here is to highlight the differences in the composition of resources with respect to countries and individual HEIs. For example, at the European level, third-party funds account on average for $21 \%$ of revenues, but this share exceeds $30 \%$ in a number of countries, and rises as high as $40 \%$ of the total revenues in some cases (Lepori et al. 2007). These differences are related to national-level variations in the composition of funding (Lepori et al. 2007), but variations can also be attributed to different capacities of individual HEIs to attract third-party funds. A second approach highlights allocation processes. In most European countries the basic operational grant constitutes the largest part of the total HEI budget-with the partial exception of UK (Lepori et al. 2007). Accordingly, the level of these grants and the criteria for their 
allocation are highly relevant when studying internal budgeting. Despite wide national differences, comparative studies display a general shift away from soft allocation based on inputs and on political negotiations towards more formalised rules where funding is based on measures of activities (e.g. students numbers) and, to a less extent, outputs such as research outputs and degrees (Jongbloed 2008).

Actors and their role in the budgeting process

The actor's perspective looks at budgeting as a process wherein different organizational actors negotiate and take decisions concerning the repartition of resources. It thus emphasizes issues such as which actors are involved in the process, their role and power in decision-making, and the grounds upon which they make decisions. Approaches to budgeting differ critically in their underlying assumptions about organizational actors, their agency and level of rationality.

Assuming an actor's perspective also relates the study of budgeting to the analysis of governance and organizational structure of HEIs. Much of the budgeting literature has adopted a view of HEIs as coalitions of departments and, accordingly, considered heads of departments as the main actors in the process (Salancik and Pfeffer 1974). However, this assumption needs to be reconsidered in view of the processes of hierarchization and strengthening of the central management which have taken place in the last decades in HEIs (Amaral 2003). Given the technical nature of budgeting and its relationships with accounting and financial management, the parallel process of strengthening and professionalization of the central administration also deserves close investigation. In this respect we consider that, rather than adhering to a clear-cut organizational model-e.g. coalitional versus centralized, it will be more relevant to investigate issues of balance of power and of how variations in budgeting are related to differences among HEIs in their internal organizational structures (see Jarzabkowski 2002).

A further relevant dimension explores organizational structure with respect to division into subunits and the definition of budgetary units. Traditionally, the higher education literature has adhered to a representation of HEIs as being organized in two levels, namely a first level of broad disciplinary groupings, such as departments, and a second level of more fine-grained units focused on specific subject areas (chairs, research centres, etc.; Clark 1983). This leads to a parallel two-level organization of budgeting where departmental budgets are decided at the central level, while chairs and research groups are budgeted at the departmental level. While this approach might still hold in many cases, some HEIs have undertaken organizational restructuring during recent years providing budgetary autonomy to schools or research centres (see Moll 2004 for an Australian case) or adopting matrix structures with distinct organizational units for research and education with separate budgets. Accurate charting of the budget structure as an outcome of the overall HEI organization may thus required on case by case basis.

Finally, a central question within this perspective concerns the changing role of the State in HEI budgeting processes, as in the European context HEI budgets move away from being part of the larger public administration budget and thus subject to direct State decision and control. As we shall discuss later, this question is closely related to the extent to which HEIs can be considered as formal organizations with a defined boundary to their wider environment (including, the State itself). 
Procedures and allocation rules: the regulative dimension

The procedural and rule-based perspective focuses on the systems of formal rules constraining the decisions of the actors in the budgeting processes and thus provides a framework within which the largely behavioral actions of the complementary actor's and power perspectives adhere. In organizational terms, it constitutes the regulatory pillar of the institutional environment (Scott 2008). As highlighted by Max Weber, formalization and rationalization are lasting change processes characterizing modern societies, where increasingly, authority and decisions have to be grounded in explicit (and rationallyjustifiable) rules (see Meyer and Rowan 1977).

For analytical purposes, it useful to distinguish between procedural and substantive rules concerning budgeting. The former define the steps through which the budget is elaborated, refined, approved and finally implemented, as well as the actors involved in each step and their role (e.g. defining voting rights). Organizational economics considers procedures-like other organizational routines - as lasting and constitutive elements of organizations, which largely determine their behaviour and way of responding to external changes (Becker 2003). While budgeting in HEIs has been traditionally represented as a largely unstructured process based on informal negotiations, it is generally considered that the transformation of HEIs towards formal organizations has also entailed the establishment of internal systems of rules and procedures (Brunsson and Sahlin-Andersson 2000).

Substantive rules are those defining how the budget should be divided among organizational subunits. These might include soft criteria, for example an understanding that units with large numbers of students should get additional resources, but also formulas, wherein allocations are calculated using some numerical parameters, for example the level of thirdparty funding earned by each subunit. The introduction of formula funding is a widespread trend at the level of higher education system (see Jongbloed 2008), but much less for internal budgeting inside HEIs (see however for the Dutch case: Jongbloed 2007).

Finally, a related area concerns specific rules and procedures governing accounting and reporting. These apparently technical aspects are highly relevant not only for insight into the budgeting process and its outcomes but also as the instantiation of actors' interests and power relationships. Internal budgeting concerns categories of resources with different characteristics and timeframes (for example, tenured positions vs. untenured). Critically, how the budget is organised and accounted for-e.g. inclusion of social costs, appropriate depreciation of capital assets-is not a purely technical issue, but is likely to impact on resources allocation since it is through these procedures administrators may attempt to constrain departmental power (Schick 1985) or to shape relationships with the State (Covaleski and Dirsmith 1988). Hence, specific competences in accounting become key assets in budgetary negotiation, both in terms of ability to provide and discuss budgetary figures and to provide supporting legitimacy to propose how funding should be distributed (Ezzamel 1994).

Traditionally, university budgets have been considered as very opaque and difficult to understand. However, pushed by new public management rationales, there has been pressure toward more transparent accounting systems, for example, allowing more finegrained control of activities and costs through full-cost accounting (Jongbloed 2000; EUA European University Association 2008).

Culture and social norms: the institutional dimension

A perspective on culture and social norms highlights the broader institutional context of budgeting accounting for regularities in actor's behaviour which goes beyond rational 
utility-based calculations (Scott 2001). Most approaches to budgeting share the view that the institutional context is relevant for budgeting and extends further than the actual content of regulations to include, for example, shared principles for allocation like equality (everybody has the right to some level of funding) and efficiency (allocation should be based on performance), conceptions of academic freedom, and the understanding of the institutional mission and goals. However, theoretical approaches critically differ in how they conceive of the relationships between institutional context and behaviour; between the two extremes of considering institutions as external limitations to purposeful behaviour in institutional economics (Williamson 2000) and considering actor's behaviour as largely determined by institutions in some neo-institutionalist approaches (Greenwood et al. 2008).

In the case of budgeting, relevant cultural and normative dimensions refer to different organizational levels: some are related to the overall institutional environment of higher education at the national level, including broader policy narratives on higher education like new public management providing specific codes on how resources should be distributed (Ferlie et al. 2008). Social norms can also be related to the specific culture of the considered HEI (Jarzabkowski 2002), for example, the importance of collegial versus managerial culture, or different representations of what a university is and how it should work. In most HEIs, social norms related to budgeting are also likely to be different across disciplinary and epistemic communities and this might well drive different expectations regarding how resources should be distributed across organizational subunits, for example, by assuming that there are specific levels of resource endowment per student for each discipline that can be justified on the grounds of different didactic practices. In many countries which introduced formula funding at the institutional level, these differences have often been taken into account through different levels of State funding per head of student and thus acquire stronger relevance for internal budgeting of universities both because of their practical and their normative implications.

\section{A review of the literature}

In this section, budgeting is recognized first as a technical device employed in order to implement organizational strategies and reach organizational goals, then as an intendedly rational but behaviourally constrained approach, as a process of negotiation among organisational actors competing for resources, as well as for power, and finally as a cultural and symbolic act to enable social norms and values through money (Wildavsky 2002). These four approaches to budgeting are related to different models of organizations - the rational versus the garbage can versus the coalitional versus the institutionalised model of organizations - and thus, they build upon the current scholarly debate on the organizational transformation of universities (Musselin 2007; Bleiklie 2009).

\section{Goal-oriented rationality and budgeting}

The fundamental approach to budgeting can be characterized as the rational approach: in this perspective, budgeting is an instrument in the hands of central administrators to achieve organizational goals and manage environmental relationships (Jongbloed and van der Knoop 1999). This approach assumes that HEIs are rational organizations with their own hierarchy of objectives and that they try to maximize the achievement of these objectives under environmental and resources constraints, taking also into account nonsubstitutability of resources and the presence of large irreversibility (Bonaccorsi and 
Daraio 2007). This approach links budgeting to incentive systems, but also to strategic decision-making (Jarzabkowski 2002).

In the rational approach, national funding systems set incentives for organizational behaviour, while HEIs reshape their internal allocation to create incentives for organizational units in order to respond to policy pressures and, in particular, to performance-based funding. The rational approach suggests purposeful behaviour: HEIs do not borrow national funding schemes, but implement internal budgetary systems allowing them to best answer to direct policy pressures, as documented in a study on Dutch HEIs (Jongbloed 2007).

In the literature, the rational model is mostly related to a view of organizations focusing on functional interdependencies between subunits in the production process, emphasizing the relevance of systemic power and rational planning for organizational success (Astley and Zajac 1991).

To take into account the decentralized organization of universities, educational economics has developed approaches to budgeting where responsibility is delegated to organizational units, for example, establishing cost/profit centres and making them responsible for profit and losses (Massy 1996b). The new public management literature also points towards devolution of budgeting responsibility to departments, a pattern which has been empirically demonstrated in some studies (Jarzabkowski 2002; Zahirul 2006).

A first approach, derived from the theory of multidivisional companies, is setting incentives through the creation of internal markets (transfer pricing; Jongbloed and van der Knoop 1999). Under conditions of maximization of profit of subunits, this approach allows the modelling of how central management can influence the balance between research and education through incentive schemes (Gautier and Wauthy 2007). A second approach is grounded on principal-agent theory (for a review see Eisenhardt 1989). Principal-agent represents central management and departments as independent actors with their own goals acting to maximize their utility. Central management (as principal) delegates the execution of organizational tasks - performing education and research - to departments in exchange for the transfer of financial resources (Ferris 1992). Formalized applications of the theory allow precise prediction of the expected allocation of resources if utility functions can be specified as well as under equilibrium conditions. Such models are difficult to test in cases of HEIs (Johnes 1999). However, softer versions of the theory that entail behaviouraloriented predictions, such as that an increasing independence of the central management should lead to increasing use of incentive schemes and control mechanism, are somewhat open to be empirically tested through comparative studies.

Empirical evidence of rational budgeting is, at best, partial and contested. While some studies show formalisation of the budgeting process, it is difficult to establish to which extent this is related to the achievement of organizational goals, rather than to power and social conformity, while there is evidence that formal and rational approaches go together with a large deal of power-based negotiations (Thomas 2000). A study of a Canadian university also shows that a rational approach to budgetary cuts might be dysfunctional because of structural constraints - budgetary cuts are limited by the existence of tenured positions-and because not taking into account the internal power balance makes it not work in practice (Hardy 1988). Evidence that incentive schemes work as predicted by economic theory - i.e. linking funding to performance - is documented in the case of individual researchers (Laudel 2006), but is less apparent at the HEI level (see however Jongbloed 2007). Issues of aggregation from the individual to the organizational level and, relatedly, of the possibility of specifying a production function at the departmental or organizational level, are lasting and contentious issues in educational economics. 
Bounded rationality and garbage cans: budgeting in an organized anarchy

We begin our critique of the rational budgeting process using the work of the Carnegie group, which identified both cognitive deficiencies and behavioural irregularities such as bounded rationality, satisficing and problemistic search which suggest that decision making may be intendedly rational but that neither processes nor outcomes necessarily follow the rational model (March and Simon 1958; Cyert and March 1963). This work was subsequently leveraged into what has become known as the Carnegie model of decision making; the chief characteristic of which is coalition formation. Coalitions in organizations arise for two reasons: First, organizational strategic goals are often ambiguous and departmental operational goals are often inconsistent. The result is both uncertainty and conflict. Decision-makers must therefore bargain among themselves to form coalitions around shared goals, problem definitions and priorities. Second, human cognitive limits and their behavioural consequences also contribute to coalition formation. Limits of time, resources and attention contribute to bounded rationality. Satisfying-the acceptance of satisfactory versus optimal solutions - takes place. Decision makers undertake problematic search: they look for solutions in the immediate area of the problem instead of considering a broad range of possible solutions. Coalitions allow decision makers to share information, reduce ambiguity and build consensus.

These ideas have found application in budgetary research through the theory of (process) incrementalism developed in a budgetary context by Wildavsky (1964). This theory refers to a pattern of marginal change in final allocation outcomes relative to some known base, typically the previous budget. The approach provides stable expectations for budgetary decision makers and reduces the burden of analysis for participants in the process (Davis et al. 1966). An alternative approach, called the theory of serial judgment (Padgett 1980) draws in both satisficing (Simon 1957) and ambiguity in organizational choice (March and Olsen 1976). The serial judgment budgeter also starts with an historically given allocation outcome but then systematically adjusts this outcome by cycling through discrete neighbouring alternatives. Empirical work by Padgett (1980) suggests that process incrementalism is favoured when overall budget levels must be determined but that the greater flexibility of serial judgment gives superior outcomes when the problem is allocational change.

Incrementalism was a fair description of budgetary processes in HEIs until the 1970s. Studies from that period demonstrate that, at least in the short and medium term, past allocation was the best predictor for current level of allocation (Pfeffer and Moore 1980). Since then, however, incrementalism has increasingly come under pressure as a budgeting practice which does not allow efficient and strategic allocation of resources (Massy 1996a) and there is some evidence that it has been replaced by other approaches-such as rulebased allocation - both in HEIs and in public budgets (Wildavsky and Caiden 2004). However, a closer empirical look might be useful to determine the extent to which incrementalism remains active in some aspects of HEI budgets in general as well as representing variations across individual HEIs as a function of jurisdiction or organizational characteristics.

The political model: budgeting as power-based negotiation

Borrowing from the work of both the Carnegie group and exchange theory, Pfeffer and Salancik reject the view of organizations as characterized by a unique goal and a ordering of preferences shared by all organizational participants; rather, organizations are 
recognized as coalitions of subunits with different objectives and preferences. The coalitional model argues that forms of decision based on generally agreed upon rules can be employed only when there is a basic agreement on goals and casual connections between actions and results. Soft decisions based on judgments and compromise among groups pursuing competing interests become necessary to resolve internal goal conflicts (Pfeffer and Salancik 1974). Introducing concepts from exchange theory (Emerson 1962) and strategic contingency theory (Hickson et al. 1971) allowed Pfeffer and Salancik to then push the critique of rational decision processes to incorporate the active use of power and politics, particularly under circumstances in which there is high uncertainty about problems and priorities.

The political nature of budgetary allocation in universities is considered functional to their loosely coupled organization (Weick 1976) and to the uncertainty of technology where rational approaches would be dysfunctional (Hardy 1988). These studies conceive universities as loosely coupled coalitions of departments, which negotiate internal allocation of resources, based on consideration of relative power. Since use of power has its own costs - in terms of time and effort devoted to influence organizational decisions, this approach predicts that use of power is more relevant in periods of scarcity, when conflicts are more severe and departments need to make use of their power for getting resources. It is also expected that in periods of scarcity powerful departments are able to increase their share of resources, whereas in periods of abundance flatter allocations are adopted (Hills and Mahoney 1978).

Following Resource Dependence Theory (Pfeffer and Salancik 1978), organizations are considered as open systems interacting with their environment and whose survival depends from the ability of ensuring a continuous flow of resources; to cope with environmental uncertainty organizations thus strive to have control on critical resources which are essential for their survival. Hence, power is a function of the ability of subunits to ensure critical resources for the organizations and, consequently, power-driven internal allocation is also conductive to organizational success (Pfeffer and Moore 1980). Empirical studies on US universities showed that a department's power is essentially related to student enrolments in their programs and their ability to provide external grants and contracts (Salancik and Pfeffer 1974; Pfeffer and Moore 1980; Hills and Mahoney 1978).

Following studies broadened the notion of power by also considering centrality with respect to organizational priorities, as well as the negotiating strategies of the heads of the units as these are expected to be different between central and peripheral units (Dozier Hackman 1985).

The contribution of this stream of research has been to provide a framework to understand the role of power in budgetary negotiations within universities, to provide some empirical evidence on its determinants and to demonstrate that departmental power can be functional to organizational success as a result of its connection with the acquisition of critical resources. In terms of an HEI's relationships with its environment-as well as with public policies - this drives our thinking toward budgeting as highly adaptive organizational behaviour, where HEIs move towards activities which facilitate the acquisition of critical resources such as degree programs that will attract high number of students or research concentrations that will attract third-party funding.

The neo-institutionalist approach: investigating the social order of budgeting

A third critique of the rational budgeting model rests on neo-institutionalist approaches to organizational practices, which consider that legitimacy and conformity to social norms are 
required for organizational survival and that organizational practices are limited by socially acceptable models rather than by considerations of efficiency (Meyer and Rowan 1977; DiMaggio and Powell 1983). In public institutions like universities, budgeting systems are one of the most visible organizational practices where pressures for conformity appear.

Empirically, there is evidence that HEIs tend to adopt the national allocation models for their budgeting. In Spain, different regional funding models have a remarkable impact on internal budgeting procedures of the universities (Lopez Gonzales 2006). An Australian study also shown that most universities there adopted the national allocation model as it tended to solve internal power conflicts thanks to its legitimacy, even when the national model was used only once in order to level off disparities between institutions (Watts 1982). Thus, this approach emphasizes the function of budgeting as a conformity action driven by legitimacy rather than purely as a means of improving internal operations (as in the rational approach) or to reward the most powerful units (as in the political approach).

Unlike other organizational practices which allow for decoupling between ceremonial compliance and practical operations, budgeting systems have at the same time practical implications. While playing the game of conformity towards the State in order to get more resources, organizational actors need also to take into account the implications for the internal repartition of resources and organizational power (Covaleski and Dirsmith 1988). In the case of the University of Wisconsin they studied, the practical implications of conforming to the budgeting categories imposed by the State in terms of funding volume and internal repartition were felt to be so negative that the University openly defied the existing social order of budgeting.

Case studies from a neo-institutionalist perspective demonstrate that, behind its apparent rationality and objectivity, budgeting presents a set of socially accepted practices which are largely infused by power relationships and the reproduction of control structures inside the organization (Covaleski and Dirsmith 1988; Ezzamel 1994). Such institutional entrepreneurship demonstrates a large deal of purposeful agency by organizational actors in order to invent budget models and categories in pursuit of more resources. For example, in his work on a UK university, Ezzamel (1994) showed how a group of actors were able to mobilize resistance to the budgetary cuts proposed by the central administration thanks to their specific competences in accounting, as well as through compliance to institutional myths, such as academic freedom, job security and liberal work practices.

These studies also show the critical role of negotiations and power coalitions between key actors during phases of reform. As a Swedish case study demonstrates, while apparently simple in its principles, the introduction of new funding system at the national level entailed a complex set of negotiations between political actors and the universities themselves, where issues of internal accounting and budgeting became entrenched with national allocation rules and change was possible only when stable coalitions of actors were built (Modell 2006).

\section{Appraisal and directions for future research}

The literature review above highlights strengths and weaknesses of the different traditions of study on budgeting in the context of higher education. These works provide substantial advances on our understanding of the main perspectives on budgeting, namely resources, actors and power, procedures and rules and, finally, social institutions. The main objective of most of these studies was to test a specific theoretical perspective, thus contributing to enrich our broad understanding of organizations and budgeting processes overall. 
The more focused agenda of higher education studies leads inevitably to a need to address questions like how budgeting processes are related to other organizational characteristics of HEIs, as well as to their change across time, the influence of changing national funding systems on budgeting, and the impact of budgeting on HEI activities and organizational success. Addressing empirically these questions is thus likely to require the use and blending of different theoretical perspectives as researchers attempt to understand how power and rules, resources and institutions coexist and coevolve in universities.

Second, the current scholarly debate on the organizational nature of HEIs tends to focus on their complex and multifaceted nature, as well as on the fact that there is a great deal of variation in organizational forms among individual HEIs related to their characteristics, history and environmental conditions (Musselin 2007). National policy environments also greatly differ in their characteristics and in the extent to which new rationales, like New Public Management, have been introduced in higher education steering and funding (Ferlie et al. 2008; Bleiklie et al. 2011b). In this context, there is limited justification for a single theoretical framework for studying higher education budgeting.

Trying to integrate theoretical perspectives on HEIs in general would be a risky and potentially meaningless task. However, performing this integration around some specific research issues in budgeting seems more feasible (Covaleski et al. 2003). Specifically, in the following sections of the paper, we focus on two main topics, namely: (1) analysing the relationship between the transformation of HEIs toward formal organizations and strategic actors and changes in budgeting and (2) understanding the mechanisms through which budgeting in HEIs is influenced by changing environmental conditions and, especially, by reforms in national funding systems.

As it will be clear from the following, these questions are essentially of a comparative nature, meaning they require the systematic comparison of organizational and environmental characteristics with budgeting processes across different HEIs and countries.

\section{Organizational restructuring of HEIs and budgeting processes}

A substantial body of literature has emerged in higher education studies concerning the transformation of HEIs into formal organizations (Brunsson and Sahlin-Andersson 2000; Krücken and Meier 2006) and/or into strategic actors that are able to define their own goals and strategies and to implement them through internal organizational processes (Whitley 2008).

We argue that budgeting is a central locus where these processes can be observed and measured: first, control and management of financial resources is a central set of organizational processes which are critical for organizational control; second, given its direct connection with resources and organizational activities, budgeting is a place where the practical implications of organizational change can be observed more directly than, for example, looking at formal structures and strategic documents.

In the following section, we discuss these relationships with respect to three central processes, namely the definition of organizational boundaries, the establishment of an organizational hierarchy and, finally, the introduction of formal rules and procedures for managing the organization.

\section{Defining organizational boundaries in budgeting}

The existence of an organizational budget-i.e. a clearly identified perimeter of which expenditures (and revenues) belong to the organization-as well as the ability of the 
organization to manage them-should be considered as key presupposition of considering an HEI as a formal organization. Accordingly, the study of budgeting is a good place to assess the degree of definition (openness or permeability) of organizational boundaries.

In the European context, comparative studies document an increase in the autonomy of HEI concerning financial matters in the recent years. Evidence includes the attribution of a global budget, the transfer of responsibility to decide on the budget from the State to university boards and the possibility of creating reserves and, to a lesser extent, to ability to borrow money from financial markets (CHEPS 2010). Yet, these studies also display wide differences between countries with respect to autonomy and there are still cases where the final decision on the budget is a State competence. Availability of data is a further rough indicator of autonomy in budgeting. In a recent European-level data collection on HEIs, data on university budgets were collected for almost all countries except France, where the tenured personnel are paid directly by the State and thus no aggregate figures on university budgets are published (Daraio et al. 2011). Moreover, budgetary data usually cover only personnel and current expenditures, while in many countries infrastructures and buildings are owned by the State and the related expenditures are included in State accounts.

But even where the State does not have formal powers concerning budgets, substantial influence may still be exerted through representation on university boards, informal ties and negotiations.

We argue that most European HEIs are likely to be situated between the two extremes of full control and responsibility on their budget on one side and a setting where both the level and the repartition of the budget are fully determined by the State as a part of public administration budgeting processes on the other. A more nuanced approach to the organizational nature of HEIs would then consider them as inherently open and penetrated organizations (Bleiklie et al. 2011a) and use the analysis of budgeting as a tool to examine the (varying) degree of control individual HEIs have on different organizational processes, as well as the role of the State in organizational decisions.

New power balances: the coalition model of budgeting revisited

As shown in the literature review, a range of studies have focused on the relevance of power to explain budgeting processes and have empirically demonstrated that power is related to specific features, like the ability of subunits to acquire critical resources and their efficacy regarding the strategic objectives of the organization. While most of these studies are rooted in the coalition model of organizations, we suggest revisiting this approach in light of the recent literature on organizational restructuring of HEIs and, especially, the strengthening of the power of central bodies (Bleiklie et al. 2011a).

First, as power in budgeting displays direct implications in terms of available resources, its distribution among organizational actors is likely to provide relevant information on the overall organization of HEIs and relative importance of different actors-boards versus rectors versus departments-which is less subject to the risk of showing ritual and ceremonial behaviours than other sources of information (like organizational charts). Empirically, this question can be addressed in two, largely complementary ways: first, by analysing the formal processes of budgeting and the role of different actors (e.g. their involvement in decision-making committees or who formally approves the budget) and, second, asking organizational actors to specify which model best corresponds to their representation of the current budgeting process (investigating the perceived power of actors). Contrasting these two measures will also be relevant to understand to what extent budgeting power is related to structural positions in contrast to political negotiations. 
Table 1 Models of repartition of power

\begin{tabular}{|c|c|c|}
\hline & Strong departmental power & Weak departmental power \\
\hline $\begin{array}{l}\text { Strong } \\
\text { central } \\
\text { power }\end{array}$ & $\begin{array}{l}\text { Political model } \\
\text { Negotiation is important due to both parties } \\
\text { having significant power }\end{array}$ & $\begin{array}{l}\text { Rational model } \\
\text { Centralised budgeting model with } \\
\text { bureaucratic processes }\end{array}$ \\
\hline $\begin{array}{l}\text { Weak } \\
\text { central } \\
\text { power }\end{array}$ & $\begin{array}{l}\text { Garbage can model } \\
\text { Chaotic interaction of strong subunits without } \\
\text { centralized control. Incrementalism }\end{array}$ & $\begin{array}{l}\text { Institutional model } \\
\text { Allocation dictated by social norms or by } \\
\text { external actors (e.g. the State) }\end{array}$ \\
\hline
\end{tabular}

Second, we suggest that differing degrees of centralisation of budgeting processes might also drive different models of budgeting processes. It is useful in this respect to distinguish between vertical power, i.e. the ability of the central administration to allocate resources based on its own objectives, and horizontal power, i.e. the differential ability of departments to drive the allocation of resources as compared with other departments.

By crossing these two dimensions, four models of power in budgeting (Table 1) can be recognized: the rational model applies where central administration decides on goals and strategic priorities and sets the internal allocation of resources. The political model applies when both central administration and departments have substantial power so that goals and strategic priorities become subject to bargaining. When strong departments must reach budgeting decisions under weak central control, conditions of organized anarchy may prevail and process incrementalism might provide insights into the outcome. Finally, the institutional model could be seen as a case where no organizational actor has adequate power to drive the allocation of resources according to its own interests, but this is done following broadly accepted conventions on how resources should be distributed. Where there is substantial uncertainty in the environment due to a regulative or normative void, the tendency of individual organizations to 'play safe' may yield mimetic responses unconnected with organizational interests. Where strong social or professional norms dominate, conformity arises from normative pressures. Finally, jurisdictions in which regulation by the State is substantial may result in pressures to conformity that are truly coercive in nature (de Boer et al. 2007).

In practical terms, the outcome of this discussion is that the good functioning of different budgeting models is related to specific conditions in terms of organizational structure, identity and balance of power and thus the key issue is the fit between the two, rather than picking the theoretically best possible model. For instance, a negotiation-based model will hardly be conductive to organizational success if departments are weak actors, i.e. not able to pursue their own interests. Similarly, a rational model based on principal-agent theory will fail if departments are so strong that the central power will not be able to control departmental agency leading to a high risk of shirking and of coalitions between departments jeopardizing linked incentive systems.

Analyzing rationalization processes in HEIs. Power-based versus rule-based allocation

Rationalization processes-i.e. the tendency for organizational decisions to be based on generally-valid rules and procedures rather than on bargaining based on power-is considered as a central phenomenon in the transformation of HEIs into formal organizations (Meyer and Rowan 1977). However, two issues are at stake here. First, we need to understand the extent to which such processes have actually taken place. Second, we need to understand the function of adopted rules in use, especially whether that function is 
genuinely rational, only intendedly rational, i.e. subject to substantial limitation and negotiation, or even primarily symbolic.

a. Empirically investigating the relative role of rules vs. power in current budgeting practices, between the extremes of fully formalized systems and fully negotiated systems, where no explicit and shared rules are in place is relevant for two reasons. First, such an analysis can shed light on the extent of the rationalization processes in HEIs overall and, second, it can illuminate the characteristics of the budgeting process, as political and incremental budgeting are expected to display a lower level of rationalization than rational (incentive-based) and institutions-based budgeting.

Two measures of these characteristics can be identified. First, the analysis of the formalization degree of budgetary allocation can be determined by examining the existence of rules, the level of discretionary criteria concerning their application and, the extent to which rules are public and known by organizational actors. Second, interviews of organizational actors can surface their representations of the relative role of rules vs. power in budgeting practices (e.g. see Dozier Hackman 1985).

b. Budgeting theories are profoundly different in their interpretation of the mechanisms driving the establishment of formal rules. Whereas rational models interpret rules as tools to realize efficient allocation of resources, political economy models conceive rules as instruments strategically used by actors in order to establish their power (carddecking; McCubbins et al. 1987) and neo-institutionalist approaches conceive rationalization as a ritual tool intended to legitimize the organization in the eyes of the State and other relevant audiences (Meyer and Rowan 1977). More nuanced studies in the neo-institutionalist tradition show that the introduction of budgeting rules does not replace negotiations among actors, but rather frames them differently, while rule systems - even if justified from apparently rational grounding - by and large also technically mask their interests and power (Ezzamel 1994; Moll 2004).

While these issues are best addressed by longitudinal case studies, two simpler measures can be devised which allow for systematic comparisons between HEIs. First, measures of realised allocation outcomes can be examined identifying organizational actors who are best served by current allocation rules-e.g. which faculties receive more funding per head of student-to determine inconsistencies between organizational goals and the observed distribution of resources. A second approach would involve asking organizational actors about their perception of the function of rules, as well as which actors they believe are best served by current allocation rules and procedures.

\section{Responding to environmental changes}

Theoretical approaches to budgeting fundamentally differ in accounts of organizational responses to changes in the funding environment. Economics and resource dependency theorists emphasize the selection of budgeting systems by managers as tools to acquire additional resources or to improve efficiency, whereas neo-institutionalists accounts predict that HEIs adopt budgeting schemes based on conformity to social myths, norms and regulatory pressures.

This question is relevant for understanding budgeting and its implications for organizational behavior overall, but also for policy purposes, as reform in national funding systems is largely used as an instrument to steer higher education under rationalist 
assumptions-e.g. to improve the efficiency of the system by introducing competition. In this respect, changes in budgeting systems are seen as critical in order to transfer economic incentives to the "production level" of HEIs (Liefner 2003).

In the following, we discuss some approaches that, while keeping the core insights of neo-institutionalism, try to reconcile these with richer accounts of organizational agency and provide a more balanced view of how organizations react both to their technical and institutional environments (Kraatz and Zajac 1996). We organize the discussion in two parts, first exploring the extent to which features of national funding systems generate conformity and material pressures to HEIs concerning budgeting and b) considering which factors might account for variations in responses among individual HEIs.

The structure of resource space and organizational responses in budgeting

As highlighted, national funding systems include both normative and technical dimensions, as they introduce new principles for the allocation of funding-for example, emphasizing efficiency and accountable use of money-while, at the same time, allocating resources between funding streams and defining allocation criteria that impact resource availability and critical dependencies, for example, by valuing differently categories of students or modifying the share of third-party funding.

We note that markets themselves are socially constructed and institutionalized actor's spaces, where notions like rationality, economic value and efficiency are socially constructed (Biggart and Delbridge 2004; White 2002) and symbolic acts might generate economic realities (Zajac and Westphal 2004). If the introduction of performance-based allocation by a HEI is valued by students or private companies as a sign of efficiency and drives an increase of the resources flow, it is rational to introduce it even if not justified in terms of technical efficiency. Accordingly, funding systems should never be taken at their face value only, but as they are interpreted and enacted by the actors controlling economic resources.

To address the balance between conformity and resource acquisition, it is useful to characterize funding systems along the following dimensions (Jongbloed 2008):

- The overall level of resources and its evolution over time.

- The level of centralization of decisions. This dimension characterizes which actors have the power to decide on allocations and, accordingly, the importance of their valuation for HEIs. In centralized systems, allocation is decided by the State (e.g. through performance contracts), whereas in decentralized systems it is decided by users. This includes third-party funding, but also core funding calculated on the basis of other actors decisions (for example the number of students).

- The orientation of the funding decision toward inputs-for example, the costs of education, as opposed to an orientation toward outputs-for example, the number of degrees or research publications. These criteria generate a structure of the resource space, but define as well norms and rules on how allocation of resources overall should be based.

The strategic management literature (e.g. see Oliver 1991) argues that pressures for conformity will be stronger if the discretional role of the State in allocating resources is more important, for example, if a large share of the basic grant is attributed through negotiations and based on historical criteria or if other relevant actors-e.g. students or funding agencies-share the basic norms and rules for allocation of resources. On the contrary, if a funding system is highly differentiated, meaning, for example, that different 
actors decide on allocation and that these actors have different views on how HEIs should function and manage resources, then pressures for conformity will be reduced and, accordingly, HEIs will have more freedom to shape their budgeting systems following efficiency and resources acquisition approaches.

Further, it is expected that the degree of active endorsement of social norms by the State, other public actors (for example, university associations) and experts in the field, in providing clear guidelines on how budgeting should work as well as accounts of their underlying rationales, will strengthen pressures for conformity, while scarce and diminishing resources will push HEIs to depart from social norms in order to get additional resources.

Finally, we argue that the degree of alignment between normative and technical pressures will be relevant in accounting for organizational responses. If adopting social norms on budgeting does at the same time allow acquisition of additional resources-if, for example, acquisition of third-party funding should be rewarded, but at the same time its share in public funding is large and increasing, then more uniformity in HEI responses is expected, while if the two pressures are divergent, then HEIs are likely to display different responses according to their individual characteristics.

\section{Predicting organizational responses}

While earlier institutionalist literature tended to focus only on conformity and isomorphism, a rich stream of literature has more recently emerged in order to explain why individual organizations respond differently to environmental pressures (see Greenwood, Oliver, Sahlin and Suddaby 2008), integrating also insights from resource dependency theory and the strategic management literature.

a. A structural approach considers that variations in organizational responses are accounted for by the organizational position in the field. Some analyzed dimensions are the identification of the lead organizations in a field which function as models to be imitated, the role of network connections in diffusion of practices (board interlocks studies; Davis and Greve 1997), and the importance of status, as there is evidence that middle-status organizations are more subject to conformity pressures than those with highest and lowest status (Han 1994). Most of these dimensions are likely to be relevant for higher education, as for example, it would be expected that top-tier universities are less prone to imitate national funding systems than middle-tier universities.

b. An intra-organizational approach represents organizations as coalitions of actors with different cultures and professional backgrounds, driving them to follow different archetypes (or logics) in responding to environmental changes (Greenwood and Hinings 1993). Accordingly, differences in power of these constituencies-and the way changes in budgeting impact on their interests and power-might account for differences in responses to external pressures (Delmas and Toffel 2009), for example differences in the strength of management versus academics across HEIs would be expected to explain responsiveness in introducing performance-based budgeting, at least in HEIs where a political model of budgeting is relevant.

As this approach emphasizes the pluralistic character of institutional systems and the existence of different institutional logics driving behaviour (Thornton and Ocasio 1999), a related task would be to identify the main logics available in budgeting and their roots in different societal domains (professions, markets, the State). Other approaches in this 
Table 2 Factors predicting organizational responses based on conformity, respectively on acquisition of critical resources

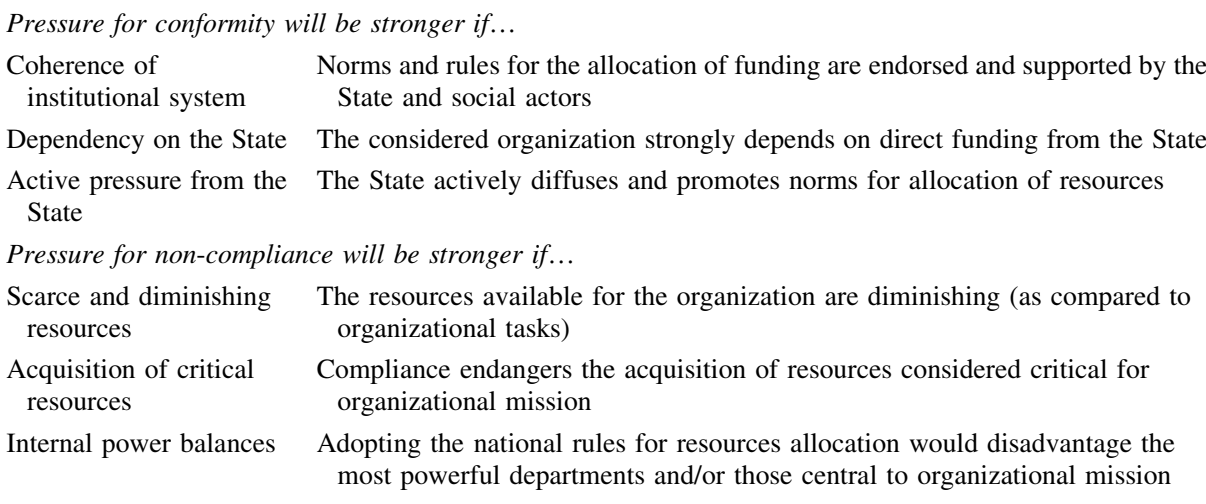

direction focus on the relevance of organizational identity, arguing that organizational responses are affected by the degree of alignment between institutional pressures and the history, social values and identity of organization itself. Indeed, a comparative study of British HEIs displays that the selection of a resource allocation system is highly sensitive to the characteristics of the organizational culture (Jarzabkowski 2002).

c. Strategic decisions under institutional constraints. Finally, the strategic management literature emphasizes that, when faced with conformity pressures, organizations can select different strategies, from compliance to defiance (Oliver 1991, 1997).

Accordingly, most criteria used to characterize conformity and technical pressures at the system level apply also to the specific situation of individual HEIs (see Table 2).

\section{Conclusions}

There are many reasons why a better understanding of budgeting is of high relevance in the context of Higher Education Studies.

First, budgeting is a central organizational activity wherein dimensions of internal organization, normative systems and power balance interact to yield an allocation of resources which is, at the same time, a set of practical actions that distribute resources, cultural actions enacting social norms, and power actions establishing internal power balances. Thus, investigating budgeting and its variations promises a better understanding of the organizational nature of HEIs overall.

Second, budgeting plays a central role in the relationships between HEIs and their environment and, following resource dependency theory, it can be argued that much of the organizational behaviour of HEIs is driven by the quest for scarce resources. But this must be framed in a broader conception of organizational responses than that provided by Economics. Without understanding the full behavioural underpinning of budgeting, it would be hardly possible to explain organizational responses to environmental changes.

Third, new policy rationales in higher education-like new public managementincreasingly put emphasis on funding instruments as a tool to steer at distance higher education institutions. Therefore, an informed critique of the rationalist approach to budgeting implicit in funding reforms will be critically important to our understanding of 
the nature of internal budgeting, particularly the balance to be struck among efficiency considerations, the role of internal power and the quest for public legitimacy.

Despite a widespread disregard of budgeting issues in the higher education studies, our literature review demonstrates that relevant building blocks can be derived from studies on HEI budgeting done in other scholarly traditions, especially organization theory. However, in order to provide answers to some central questions in the higher education field, two significant steps forward are required. First, we must make an effort to bridge different theoretical traditions to provide meaningful approaches tailored to the complex reality of today's higher education institutions. Second, we must consider a shift in empirical strategy away from the almost exclusive use of individual case studies as an empirical ground to validate specific theoretical predictions towards comparative studies on larger samples of institutions in order to analyse variations across individual organizations, time and national systems.

Acknowledgments This work has been funded by the Swiss National Science Foundation under the European Science Foundation EUROHESC programme. The authors wish to thank for comments and discussion their colleagues in the TRUE project, namely Ivar Bleiklie, Jürgen Enders, Christine Musselin, Jeroen Huisman, Barbara Kehm, António Magalhães, Svein Michelsen, Nicoline Frølich, Stig Slipersæter, Emanuela Reale, as well as three anonymous referees.

\section{References}

Amaral, A., Meek, \& Larsen. (2003). The higher education managerial revolution?

Astley, W., \& Zajac, E. (1991). Interorganizational Power and Organizational Design: Reconciling Rational and Coalitional Models of Organization, 2(4), 339-411.

Becker, M. C. (2003). The concept of routines twenty years after Nelson and Winter (1982). A review of the literature.

Biggart, N., \& Delbridge, R. (2004). Systems of exchange. The Academy of Management Review, 29(1), $28-49$.

Bleiklie, I., Enders, \& Lepori. (2009). Some thoughts on the TRUE perspective.

Bleiklie, I., Enders, J., Lepori, B., \& Musselin, C. (2011b). New public management, network governance and the university as changing professional organization. In T. Christensen \& P. Lægreid(Eds.) Ashgate Research Companion to New Public Management Aldershot: Ashgate.

Bleiklie, I., Enders, Lepori, B., \& Musselin, C. (2011a). Universities as Penetrated Hierarchies. Organizational Rationalization, Hierachization and Networking in Higher Education.

Bonaccorsi, A., \& Daraio, C. (2007). Theoretical perspectives on university strategy. In A. Bonaccorsi \& C. Daraio (Eds.), Universities and strategic knowledge creation. Specialization and performance in Europe (pp. 3-30). Cheltenham: Edwar Elgar.

Brunsson, N., \& Sahlin-Andersson, K. (2000). Constructing organizations: The example of the public sector reform. Organization Studies, 721-746.

CHEPS. (2010). Progress in higher education reform in Europe. Funding reform. Brussels: European Commission.

Clark, B. R. (1983). The higher education system. Academic organization in cross-national perspective. Berkeley: University of California Press.

Covaleski, M. A., \& Dirsmith, (1988). An institutional perspective on the rise, social transformation and fall of a university budget category. Administrative Science Quarterly, 33(4), 562-587.

Covaleski, M. A., Evans, J. H., Luft, J. L., \& Shields, M. D. (2003). Budgeting research: Three theoretical perspectives and criteria for selective integration. Journal of Management Accounting Research, 15, $3-49$.

Daraio, C., Bonaccorsi, A., Geuna, A., Lepori, B., et al. (2011). The European university landscape: A micro characterization based on evidence from the Aquameth project. Research Policy, 40(1), 148-164.

Davis, O. A., Dempster, M. A. H., \& Wildavsky, A. (1966). A theory of the budgetary process. The American Political Science Review, 60(3), 529-547.

Davis, G. F., \& Greve, H. R. (1997). Corporate elite networks and governance changes in the 1980s. American Journal of Sociology, 103(1), 1-37.

de Boer, H., Enders, J., \& Schimank, U. (2007). On the way towards new public management? The governance of university systems in england, the netherlands, austria, and germany. In D. Jansen (Ed.), 
New forms of governance in research organizations-disciplinary approaches, interfaces and integration (pp. 137-154). Dordrecht: Springer.

Delmas, M., \& Toffel, M. (2009). Organizational responses to environmental demands: Opening the black box. Strategic Management Journal, 29(10), 1027-1055.

DiMaggio, P. J., \& Powell, (1983). The iron cage revisited: Institutional isomorphism and collective rationality in organizational fields. American Sociological Review, 48, 147-160.

Dozier Hackman, J. (1985). Power and centrality in the allocation of resources in colleges and universities. Administrative Science Quarterly, 30, 61-77.

Eisenhardt, K. (1989). Agency theory: An assessment and review. Academy of Management Review, 14, 57-74.

Emerson, R. M. (1962). Power-dependence relations. American Sociological Review, 27(1), 31-41.

EUA European University Association. (2008). Financially sustainable universities. Towards full costing in European Universities. Brussels: European University Association.

Ezzamel, M. (1994). Organizational change and accounting: understanding the budgeting system in its organizational context. 15/2, 213-240.

Ferlie, E., Musselin, C., \& Andresani, (2008). The steering of higher education systems: A public management perspective. Higher Education, 56(3), 325-348.

Ferris, J. M. (1992). A contractual approach to higher education performance: With an application to Australia. Higher Education, 24(4), 503-516.

Gautier, A., \& Wauthy, (2007). Teaching versus research: A multi-tasking approach to multi-department universities. European Economic Review, 51, 273-295.

Greenwood, R., \& Hinings, C. R. (1993). Understanding strategic change. The contribution of archetypes. The Academy of Management Journal, 36(5), 1052-1081.

Greenwood, R., Oliver, C., Sahlin, K., \& Suddaby, R. (2008). Introduction. In R. Greenwood, C. Oliver, K. Sahlin, \& R. Suddaby (Eds.), Organizational institutionalism (pp. 1-46). London: Sage.

Han, S. (1994). Mimetic isomoprhism and its effects on the audit services market. Social Forces, 73(2), 637-664.

Hardy, C. (1988). The rational approach to budget cuts: One university's experience. Higher Education, 7(2), 151-173.

Hickson, D. J., Hinings, C. R., Lee, C. A., Schneck, R. E., \& Pennings, J. M. (1971). A strategic contingencies' theory of intraorganizational power. Administrative Science Quarterly, 16(2), 216-229.

Hills, F. S., \& Mahoney, T. A. (1978). University budgets and organizational decision making. Administrative Science Quarterly, 23, 454-465.

Jarzabkowski, P. (2002). Centralised or decentralised? Strategic Implications of Resource Allocation Models., 56, 5-32.

Johnes, G. (1999). The management of universities. Scottisch Journal of Political Economy, 46(5), 505-522.

Jongbloed, B. (2000). Spending strategies. A closer look at the financial management of the European university 2000: European University Association.

Jongbloed, B. (2007). Reforming the Dutch academic research entreprise: Universities' responses to project funding and performance monitoring CHER Conference, Kassel.

Jongbloed, B. (2008). Creating public-private dynamics in higher education funding. A discussion of three options. In J. Enders \& B. Jongbloed (Eds.), public-private dynamics in higher education funding (pp. 113-138). Bielefeld: Transcript.

Jongbloed, B., \& van der Knoop, H. (1999). Budgeting at the institutional level: Responding to internal pressures and external opportunities. In B. Jongbloed, P. Maassen, \& G. Neave (Eds.), From the eye of the storm. Higher education's chaning institutions (pp. 141-164). Dordrecht: Springer.

Kraatz, M. S., \& Zajac, E. (1996). Exploring the limits of the new institutionalism: Causes and consequences of illegitimate organizational change. American Sociological Review, 61(5), 812-836.

Krücken, G., \& Meier, F. (2006). Turning the university into an organizational actor. In G. S. Drori, J. W. Meyer, \& H. Hwang (Eds.), Globalization and organization. World society and organizational change (pp. 209-240). Oxford: Oxford University Press.

Lascoumes, P., \& Le Gales, (2007). Introduction: Understanding public policy through its instrumentsfrom the nature of instruments to the sociology of public policy instrumentation. Governance: An International Journal of Policy, Administration, and Institutions, 20(1), 1-21.

Laudel, G. (2006). The art of getting funded: How scientists adapt to their funding conditions. Science and Public Policy, 33(7), 489-504.

Lepori, B., Benninghoff, M., Jongbloed, B., Salerno, C., \& Slipersaeter, S. (2007a). Changing models and patterns of higher education funding: Some empirical evidence. In A. Bonaccorsi \& C. Daraio (Eds.), Universities and strategic knowledge creation. Specialization and performance in Europe (pp. 85-111). Bodmin, Cornwall: MPG Books Limited. 
Lepori, B., Dinges, M., Reale, E., Slipersaeter, S., Theves, J., \& Van den Besselaar, P. (2007b). Comparing the evolution of national research policies: What patterns of change? Science and Public Policy, 34(6), $372-388$.

Liefner, I. (2003). Funding, resource allocation, and performance in higher education systems. Higher Education, 469-489.

Lopez Gonzales, M. J. (2006). Towards decentralized and goal-oriented models of institutional resource allocation: The Spanish case. Higher Education, 51(4), 589-617.

Massy, W. F. (1996a). A dynamic equilibrium model for university budget planning. Management Science, 23(3), 248-256.

Massy, W. F. (1996b). Resource allocation in higher education.

McCubbins, M., Noll, R., \& Weingast, B. (1987). Administrative procedures as instruments of political control. Journal of Law Economics and Organization, 3(2), 243-277.

Meyer, J. W., \& Rowan, B. (1977). Institutionalized organizations: Formal structure as myth and ceremony. The American Journal of Sociology, 83(2), 340-363.

Modell, S. (2006). Institutional and negotiated order perspectives on costs allocations: The case of the Swedish university sector. 15(2), 219-251.

Moll, J. \& Zahirul. (2004). Rational-legal budgeting, notions of legitimacy and power within a university environment: A case study.

Musselin, C. (2007). Are universities specific organisations? In G. Krücken, A. Kosmützky, \& M. Torka (Eds.), Towards a multiversity? Universities between global trends and national traditions (pp. 63-84). Bielefeld: Transcript.

Oliver, C. (1991). Strategic responses to institutional processes. The Academy of Management Review, 16(1), 145-179.

Oliver, C. (1997). Competitive advantage: Combining institutional and resource-based views. Strategic Management Journal, 18(9), 697-713.

Padgett, J. F. (1980). Managing gargabe can hierarchies. Administrative Science Quarterly, 25(4), 583-604.

Pfeffer, J., \& Moore, W. L. (1980). Power in university budgeting: A replication and extension. Administrative Science Quarterly, 25, 637-653.

Pfeffer, J., \& Salancik, G. R. (1974). Organizational decision making as a political process: The case of a university budget. Administrative Science Quarterly, 19(4), 135-151.

Pfeffer, J., \& Salancik, G. R. (1978). The external control of organizations. A resource dependence perspective. New York: Harper \& Row.

Salancik, G., \& Pfeffer, J. (1974). The bases and use of power in organizational decision making: The case of a university. Administrative Science Quarterly, 19(4), 453-473.

Schick, A. (1985). University budgeting: Administrative perspective, budget structure, and budget process. The Academy of Management Review, 10(4), 794-802.

Scott, W. R. (2001). Institutions and organizations. Thousand Oaks, California, USA: Sage.

Scott, W. R. (2008). Institutions and organizations. Ideas and interests. Thousands Oaks: Sage.

Simon, H. (1957). Models of man: Social and rational. New York: Wiley.

Thomas, H. (2000). Power in the resource allocation process: The impact of "rational" systems. 2, 127-137.

Thornton, P., \& Ocasio, W. (1999). Institutional logics and the historical contingency of power in organizations: Executive Succession in the Higher Education Publishing Industry, 1958-1990. The American Journal of Sociology, 105(3), 801-843.

Watts, E. W. (1982). Internal allocation of funds: Changes and challenges for Australian universities. Administrative Science Quarterly, 12, 53-69.

Weick, K. (1976). Educational organizations as loosely coupled systems. Administrative Science Quarterly, 21(1), 1-19.

White, H. C. (2002). Markets from networks. Socioeconomic models of production. Princeton, New Jersey, USA: Princeton University Press.

Whitley, R. (2008). Constructing universities as strategic actors: Limitations and variations. In L. Engwall \& D. Weaire (Eds.), The university in the market (pp. 23-37). Colchester: Portland Press Limited.

Wildavsky, A. (1964). The politics of the budgetary process. Boston \& Toronto: Little, Brown and Company.

Wildavsky, A. (2002). Budgeting. A comparative theory of budgetary processes. New Brunswick: Transaction Publishers.

Wildavsky, A., \& Caiden, N. (2004). The new politics of the budgetary process.

Williamson, O. E. (2000). The new institutional economics: Taking stock, looking ahead. Journal of Economic Literature, 38(3), 595-613.

Zahirul, H. (2006). Methodological issues in accounting research. Theories, methods and issues.

Zajac, E., \& Westphal, J. (2004). The social construction of market value: Institutionalization and learning perspectives of stock market reactions. American Sociological Review, 69(3), 433-457. 